\title{
Isparta Bölgesinden Konya Veteriner Kontrol Enstitüsü Müdürlüğüne Gönderilen Numunelerin Parazitolojik Açıdan Değerlendirilmesi
}

\author{
Mehmet Aciöz ${ }^{1}$ \\ İlç̧e Gıda Tarım ve Hayvancılık Müdürlüğ̈̈, Datça, Muğla, Türkiye.
}

Geliş Tarihi / Received: 16.11.2017, Kabul Tarihi / Accepted: 18.04.2018

\begin{abstract}
Özet: Bu çalışma; Isparta bölgesinden Konya Veteriner Kontrol Enstitüsü Müdürlüğü (KONYAVKEM)'ne gönderilen numunelerin ve sonuçların retrospektif olarak değerlendirilmesi amacıyla yapılmıştır. Bu amaçla, 2014, 2015 ve 2016 yıllarında Isparta bölgesinden KONYAVKEM gönderilen dışkı, kadavra, kan ve organlar parazitoloji laboratuvarında muayene edilmiş ve sonuçlar değerlendirilmiştir. Gönderilen 74 numuneden 44 'ünde (\% 59.4) paraziter etken tespit edilmiştir. Tüm hayvan gruplarında sonuçlar birlikte değerlendirildiğinde; Eimeria spp. \% 22.9, Cryptosporidium spp. $\% 13.5$, Toxoplasma gondii \% 8.1, Trichostrongylus spp. \% 5.4, Nematodirus spp. \% 2.7, Moniezia spp. \% 1.3, Fasciola hepatica \% 1.3, Cystacaulus ocreatus larvası \% 1.3, Coenurus cerebralis \% 1.3 ve Babesia spp. \% 1.3 olarak bildirilmiştir. Sonuç olarak, veteriner hekimlere, sivil toplum kuruluşlarına paraziter hastalıklar hakkında bilgi verilmedir. $\mathrm{Bu}$ çalışma ile veteriner parazitolojinin, Isparta bölgesinde hayvan sağlığ 1 ve yetiştiriciliği açıısından önemi vurgulanmıştır.
\end{abstract}

Anahtar kelimeler: Hayvan Sağlığı, Isparta, Paraziter Enfeksiyonlar

\section{The Parasitologic Evaluation of The Samples Sent from Isparta to Veterinerian Control Instution of Konya}

\begin{abstract}
This study aims to evaluate the samples taken throughout Isparta and sent to the Institute of Veterinerian Control in Konya (KONYAVKEM) in terms of parasitology. The feces, cadaver, blood and the organs sent to KONYAVKEM from Isparta in 2014, 2015 and 2016 were examined in the parasitology laboratory and the results were evaluated. 44 samples out of $74(59.4 \%)$ were realized to have parasitic infection. As far as the results are evaluated including all the animal species, it is stated as follows; Eimeria spp. 22.9\%, Cryptosporidium spp. 13.5\%, Toxoplasma gondii 8.1\%, Trichostrongylus spp. 5.4\%, Nematodirus spp. 2.7\%, Moniezia spp. 1.3\%, Fasciola hepatica 1.3\%, Cystacaulus ocreatus larvae 1.3\%, Coenurus cerebralis 1.3\% and Babesia spp. 1.3\%. This ultimately shows that veterinerians and nonprofit organizations must be informed about parasitic disease. The focus of this study is that veterinerian parasitology is important for animal health and breeding in Isparta.
\end{abstract}

Key words: Animal health, Isparta, Parasitic infection

\section{Giriş}

Afyonkarahisar, Antalya, Burdur, Konya ve Isparta'yı da kapsayan bölgeye göller yöresi denilmektedir. $36.672 \mathrm{~km}^{2}$ alana sahip bölgenin fazla yağış alması sebebiyle bu bölge büyükbaş ve küçükbaş hayvan yetiştiriciliğinde önemli bir potansiyele sahiptir [1].

Özellikle Isparta ekonomisinde hayvan yetiştiriciliği önemli bir yer tutmaktadır. 2016 yılı Türkiye İstatistik Kurumu (TÜİK) verilerine göre Isparta İli'nde 149382 adet sığır, 347 manda, 250158 koyun ve 304697 adet keçi mevcuttur [6].

Küçükbaş hayvan yetiştiriciliğinde temel beslenme aracı olan çayır, mera ve yaylaların korunma-
S1 ve en etkin şekilde değerlendirilmesi, hayvancılık ekonomisine (et, süt, yapağı) büyük katkı sağlayacaktır. Ayrıca köy ve mezralardaki insanların yaşam standartlarının artması, büyükşehirlere göçünde önlenmesinde büyük katkısı olacaktır[4].

Türkiye'de tarımsal verimlilik ve tarım dışı istihdam düşük, tarımın nüfus içindeki payı kabaca $\% 33$ ve tarımın gayri safi milli hasıladaki payı kabaca \%12'dir. Gelişmiş ülkelerin çok gerisinde kalmıştır. Bu durum hayvancılık sektörüne olumsuz yönde etkilemiştir [19]. Paraziter hastalıklar, hayvanlarda verim kayıplarına neden olarak ülke ekonomisini olumsuz yönde etkilemektedir. Bunlar et, süt, döl verimi, yavru kayıpları olarak sıralanabilir $[21,24,25]$. 
Paraziter kökenli enfeksiyonlar, parazitin türü, morfolojik özellikleri, sayıları, yerleştikleri organ ve dokular, beslenme şekillerine göre farklılık göstermekle birlikte, kilo-besi kaybı, göçleri sırasında organ ve dokularda tahribat, ishal, anemi, sanc1 ve ciddi olgularda ölüme yol açabilecek çeşitli patojenitelere sahiptir [12,25].

Paraziter hastalıklardan bazıları zoonoz karakterde olmalarından dolayı da önem arz ederler. Sağlık Bakanlığı verileri göre, 2005-2010 yılları arasında insanlarda 2057 kist hidatik vakası rapor edilmiştir [5].

Bu çalışmada, 2014, 2015 ve 2016 yıllarında Isparta İli’nden KONYAVKEM'e gönderilen numunelerin parazitoloji açısından irdelenmesi amaçlanmıştır.

\section{Materyal ve Metot}

Araştırma materyalini 2014, 2015 ve 2016 yıllarında Isparta İli'nden KONYAVKEM'e gönderilen numuneler oluşturmuştur. Bu amaçla "Hayvancılık Bilgi Sistemi” (HBS)'nden gönderilen marazi maddeler ve paylaşılan protokoller incelenmiştir [3]. Bu protokollere ait veriler (ilçe, yıl, adet, yaş, nevi ve türü) tek tek kontrol edilmiştir. Gönderilen numuneler rutin teknikler kullanılarak çalışılmıştır. Kan protozoonları açısından giemasa boyası ile hazırlanan frotiler incelenmiştir. Otopsi yapılan hayvanlar erişkin parazitleri görmek amacıyla makroskopik olarak muayene edilmiştir. Kan serumları rutin ELISA yöntemiyle bakılmıştır. Dışkı örnekleri önce makroskobik, daha sonra sirayla direkt bak1, flotasyon ve sedimentasyon yöntemleriyle mikroskobik olarak incelenmiştir [16]. Sonuçlar tartışılmış ve Isparta'da görülen parazitler hakkında genel bir bilgi elde edilmiştir.

Bu çalışma için HADMEK' in 05.06.2009 tarih ve 12 sayılı kararına istinaden etik kurul onayı alınmamiştır.

\section{İstatistiksel analiz}

$\mathrm{Bu}$ çalışmada elde edilen verilerin istatistiksel analizi için, Statistical Package for the Social Sciences for Windows 16.0 (SPSS Inc.; Chicago, IL, ABD) paket programı kullanılmıştır.

\section{Bulgular}

Isparta'dan 3 y1lda (2014, 2015 ve 2016) KONYAVKEM Parazitoloji Laboratuarına, koyun, keçi ve sığır cinsi hayvanlara ait toplam 74 adet marazi madde gönderilmiştir. İncelenen 74 marazi maddeden 44'inde paraziter etken tespit edilmiştir. Gönderilen numunelerde enfekte hayvan sayis1 ve incelenen hayvan sayısı Şekil 1'de gösterilmiştir. Hayvan gruplarına göre tespit edilen parazit cins/türleri ve oranları tablo 1'de sunulmuştur.

Tablo 1. İncelenen hayvanlara göre parazit cins/türleri ve oranları

\begin{tabular}{|c|c|c|c|c|c|c|c|c|c|c|c|c|}
\hline \multirow{2}{*}{ Parazit } & \multicolumn{2}{|c|}{ Koyun } & \multicolumn{2}{|c|}{ Kuzu } & \multicolumn{2}{|c|}{ Keçi } & \multicolumn{2}{|c|}{ Oğlak } & \multicolumn{2}{|c|}{ Sığgır } & \multicolumn{2}{|c|}{ Toplam } \\
\hline & EHS $^{*}$ & $\%$ & EHS & $\%$ & EHS & $\%$ & EHS & $\%$ & EHS & $\%$ & EHS & $\%$ \\
\hline Eimeria spp. & 1 & 4,5 & 11 & 33,4 & 3 & 37,5 & 2 & 18,1 & - & - & 17 & 22,9 \\
\hline Cryptosporidium spp. & - & & 5 & 16,1 & - & - & 3 & 27,2 & - & - & 10 & 13,5 \\
\hline Toxoplasma gondii & 6 & 27,2 & - & - & - & - & - & - & - & - & 6 & 8,1 \\
\hline Trichostrongylus spp. & 1 & 4,5 & 1 & 3,2 & 2 & 25 & - & - & - & - & 4 & 5,4 \\
\hline Nematodirus spp. & 1 & 4,5 & - & - & 1 & 12,5 & - & - & - & - & 2 & 2,7 \\
\hline Moniezia spp. & - & & 1 & & - & - & - & - & - & - & 1 & 1,3 \\
\hline Fasciola hepatica & 1 & 4,5 & - & - & - & - & - & - & - & - & 1 & 1,3 \\
\hline Cystacaulus ocreatus larvası & - & & - & - & 1 & 12,5 & - & - & - & - & 1 & 1,3 \\
\hline Coenurus cerebralis & 1 & 4,5 & - & - & - & - & - & - & - & - & 1 & 1,3 \\
\hline Babesia spp. & 1 & 4,5 & - & - & - & - & - & - & - & - & 1 & 1,3 \\
\hline
\end{tabular}

*EHS: Enfekte Hayvan Sayıs1 


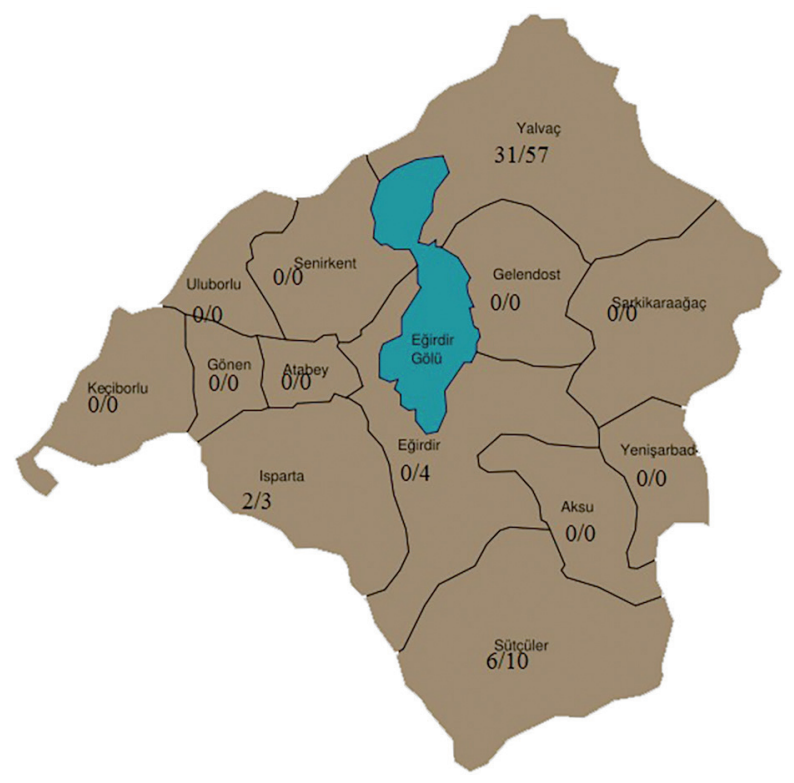

Şekil 1. Enfekte bulunan hayvanların ilçelere göre dağ1lımı (Enfekte hayvan sayısı/incelenen hayvan sayıs1).

\section{Tartışma ve Sonuç}

Isparta ilinde parazitoloji alanında yapılan çalışmalar çok sınırlıdır. Demirci ve ark. 2003 yılında yaptıkları çalışmada, Isparta'nın da içinde bulunduğu göller bölgesinin insan fasciolosisi için endemik olduğunu bildirmişlerdir [10]. Bizim çalışmamızda da koyunlarda \% 1.3 oranında fasciolosis bildirilmiştir. $\mathrm{Bu}$ hastalığın yöre insanını ve hayvan sağlığını tehdit edebileceğine düşünülmektedir.

Burdur yöresinde buzağı ve danalarında \% 26.5, Afyon ilinde sığırlarda \% 26.5, Bingöl'de keçilerde $\%$ 61.5, koyunlarda \% 56, Adana, Mersin ve Osmaniye gelen oğlaklarda \% 23.53 oranında, Eimeria spp. enfekte olduğu bildirilmiştir $[8,11,15,17]$. $\mathrm{Bu}$ çalışmada da \% 22.9 oranında Eimeria spp. bulunmuş olup yukarıda belirtilen çalışmalar ile uyumludur.

Van ilinde sığırlarda \% 8.14, koyunlarda \% 13.17, keçilerde \% 10.71, Nevşehir'de ishalli buzağllarda \%20.7, Aydın'da keçilerde \% 18.6, Sivas’ta buzağılarda \% 70.3, Erzurum' da buzağılarda ise \% 22.8 oranında Cryptosporidium spp. enfekte olduğu bildirilmiştir [7,9,18,20,23,]. Isparta'da bir keçi sürüsünde 3 ölü, 130 ishalli oğlakların tamamında Cryptosporidium parvum ookisti tespit edilmiştir [22]. Bu enfeksiyonunun yaygınlığg ile yapılan çalışmalarda prevalans oranlarının farklı olması, al1- nan numunelerin, hayvanların sağlık durumu, yaşı ve sürülerde salgın olup olmaması gibi faktörlere bağl1 olabileceği düşünülmektedir.

Toxoplasmosis özellikle koyunlarda abortlara ve neonetal kuzu ölümlerine neden olmaktadır. Aktaş ve ark. 1997 yılında Elazığ yöresinde yapıkları çalışmada, gebe koyunlarda \% 48.2, önceki yıl yavru atmışlarda ve kan alındığ 1 yıl yavru atan koyunlarda sirayla \%45,6, \%46,3 oranında T.gondii sero-pozitiflik saptamışlar [2]. Yapılan başka bir çalışmada, T. gondii ile sero-pozitif koyunlardan doğan kuzularda neonetal ölüm oranın \%30,7, sero-negatif annelerden doğan kuzularda bu oran \%13,6 olarak saptanmıştır [13]. Bizim çalışmamızda da koyunlarda \% 8.1 oranında $T$. gondii saptanmış olup, bu enfeksiyonun yöre koyunculuğu için tehdit oluşturabileceği düşünülmektedir.

Türkiye'de koyunlarda, coenurosis yaygınının $\% 1.3$ ile \%36.8 oranları arasında olduğu bildirilmiştir $[14,26]$. Bizim çalışmamızda \% 1.3 oranda bulunan Coenurosis cerebralis Türkiye'de bildirilen oranlar arasindadir.

Ayrıca bu çalışmada Isparta yöresinde ruminatlarda, Trichostrongylus spp., Nematodirus spp., Moniezia spp., Cystacaulus ocreatus larvas1. gibi etkenler belirlenmiştir. Hayvan yetiştiriciliği açısından verim kayıplarına neden olan bu parazitlerin var olması, herkes tarafından dikkate alınması gerektiği kanaatine varılmıştır.

Sonuç olarak, bu çalışma ile Isparta bölgesinde hayvan sağlığı ve yetiştiriciliği açısından önemli parazitler vurgulanmıştır.

\section{Teşekkür}

Katk1larından dolayı Konya Veteriner Kontrol Enstitüsü Müdürlüğü çalışanlarına teşekkür ederim.

\section{Kaynaklar}

1. Akman, Y, (1990). İklim ve Biyoiklim. Ankara: Palme Yayınc1lik, s. 319.

2. Altıntas K, Güngör C, Zeybek H, Yaralı C, (1997). SabinFeldman testi ile Ankara yöresi koyunlarında Toxoplasma gondii' nin prevalansinin saptanmast. Türkiye Parazitol Derg. 21, 63-65.

3. Anonim, (2017). HBS (Protokol Sonuç Raporu). http://www. tarim.gov.tr, Erişim tarihi: 05.01.2017.

4. Anonim, (2001). Isparta Valiliği; Isparta İli Çevre Durum Raporu. http://www.csb.gov.tr, Erişim tarihi: 12.01.2017. 


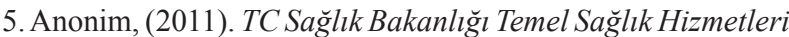
Genel Müdürlüğ̈̈ Zoonotik Hastalıklar Daire Başkanlığı. Zoonotik Hastalıklar Hizmet içi Eğitim Modülü. Sağlık Bakanlığı Yayın No: 799; Ankara,

6. Anonim, (2016). TUIK, 2016 Yılı Hayvansal üretim istatistikleri. http://www.tuik.gov.tr, Erişim tarihi: 11.01.2017.

7. Çiçek M, Körkoca H, Gül A, (2008). Van belediye mezbahasında çalışan işçilerde ve kesimi yapılan hayvanlarda Cryptosporidium sp.'nin araştırılması. Türkiye Parazitol Derg. 32, 8-1.

8. Çiçek H, Sevimli F, Kozan E, Doğan N, (2007). Prevalence of coccidia in beef cattle in western Turkey. Parasitology Research. 101, 1239-43.

9. Değerli S, Çeliksöz A, Kalkan K, Özçelik S, (2005). Prevalence of Cryptosporidium spp. and Giardia spp. in cows and calves in Sivas. Turk J Vet Anim Sci. 29, 995-999.

10. Demirci M, Korkmaz M, Kaya S, Kuman A, (2003). Fascioliasis in eosinophilic patients in Isparta region of Turkey. Infect. 31,15-18.

11. Gül A, Kılınç ŞG, (2016). Bingöl Belediye Mezbahasında kesimi yapılan koyun ve keçilerde dışkı bakılarına göre endoparazitlerin yaygınlı̆̆ııın araştırılması. Dicle Üniv Vet Fak Derg. 2, 61-66.

12. Güralp N, (1981). Helmintoloji (2 bask1). Ankara: Ankara Üniv Vet Fak Yayın:368.

13. Huffman EM, Kirk JH, Pappaioanou M, (1985). Factors associated with neonatal lamb mortality. Theriogenology. 24, 163-171.

14. Kalkan A, (1977-1978). The study fixing parasitic fona in sheep and lamb in Diyarbakur represinting to in the South East Anatolian Regions. Etlik Vet. Kont. Araşt. Enst. Derg. 4, 64-78.

15. Köse O, (2011). Burdur Yöresi Buzağı ve Danalarında Eimeria Türlerinin Prevalansı. Yüksek Lisans Tezi, Mehmet Akif Üniv Sağlık Bilimleri Enstitüsü, Burdur.
16. MAFF, (1986). Manual of Veterinary Parasitological Techniques. London: Her Majesty's Stationary Office. p. 160.

17. Özdemir R, Çaya H. Adana, (2012). Mersin ve Osmaniye İllerinden Gelen Oğlaklarda Coccidiosisin Prevalansinın Araştırılması. AVKAE Derg. 2, 6-9.

18. Paşa S, Ulutaş B, (2003). Prevalence of Cryptosporidium oocysts in goats in Aydın province. Türkiye Parazitol Derg. 27, 240-242.

19. Saraçoğlu M, (2006). Tarımsal Yapının AB Üyeliği Açısından Değerlendirilmesi, Kamu-İş İş Hukuku ve İktisat Dergisi. 4, 8-16.

20. Sarı B, Aktaş MS, Arslan MÖ, (2008). Erzurum Yöresinde Buzağılarda Cryptosporidium Türlerinin Prevalansi. Türkiye Parazitol Derg. 32, 116-119.

21. Sarıözkan S, Yalçın C, (2009). Estimating the production losses due to cystic echinococcosis in ruminants in Turkey. Vet Parasitol. 163: 330-4.

22. Sevinç F, Şimşek A, Uslu U, (2005). Massive Cryptosporidium parvum infection associated with an outbreak of diarrhoea in neonatal goat kids. Turk J Vet Anim Sci. 29: 1317- 1320.

23. Şimşek AT, et al, (2012). Nevşehir yöresindeki yeni doğan ishalli buzağllarda cryptosporidiosis' in real time PCR ve Nested PCR yöntemleri ile saptanmast, Erciyes Üniversitesi Veterinerlik Fakültesi Dergisi. 9, 79-87.

24. Şimşek S, Köroğlu E, Rişvanlı A, (2003). Ineklerde döl tutma problemi ile Fasciola hepatica arasındaki ilişki. Fırat Ü Sağ Bil Derg. 17: 227-230.

25. Toparlak M, Tüzer E, (2002). Veteriner Helmintoloji. İstanbul: İstanbul Üniv Vet Fak.

26. Uslu U, Guclu F, (2007). Prevalence of Coenurus cerebralis in sheep in Turkey. Vet Med. 63, 678-680. 